\title{
Polinização de Caryocar villosum (Aubl.) Pers. (Caryocaraceae) uma árvore emergente da Amazônia Central ${ }^{1}$
}

\author{
RODRIGO LEMES MARTINS ${ }^{2,4}$ e ROGÉRIO GRIBEL ${ }^{3}$
}

(recebido: 26 de outubro de 2005; aceito: 30 de novembro de 2006)

\begin{abstract}
Pollination of Caryocar villosum (Aubl.) Pers. (Caryocaraceae), an emergent tree in central Amazônia). Caryocar villosum is a common emergent tree of Central Amazonia. It is an important timber tree and source of fruit for men and animals. We study the floral biology, pollination, and breeding system of C. villosum. Data was collected from trees in an urban area, forest fragments and a continuous forest. Floral characteristics and plant-pollinator interactions were described and controlled hand-pollinations were undertaken to study breeding system. The flowers of C. villosum are brush-shaped, yellow and exposed above the canopy in terminal inflorescences. They have nocturnal anthesis, last for one nigth only and produce $c a .750 \mathrm{~mL}$ of nectar per nigth, which are typical traits associated with bat pollination. The especies was visited by Phyllostomus discolor and glossophaginae bats, as well as arboreal marsupials and Sphingidae moths. Hand pollinations revealed that $C$. villosum is self-compatible, but the number of fruits formed from cross-pollination was higher than that from self-pollination.
\end{abstract}

Key words - bat, Caryocar, chiropterophylly, floral biology, reproductive biology

RESUMO - (Polinização de Caryocar villosum (Aubl.) Pers. (Caryocaraceae) uma árvore emergente da Amazônia Central). Caryocar villosum é uma árvore emergente comum na Amazônia central. É uma espécie importante devido à qualidade da madeira e à produção de frutos para populações humanas e animais. No presente trabalho foram estudados a biologia floral, a polinização e o sistema reprodutivo de C. villosum. Foram observadas árvores em ambiente urbano, fragmentos de mata e mata contínua, com atenção em aspectos da interação polinizador-planta e características das flores. Foram realizadas polinizações controladas para estudo do sistema reprodutivo. As flores de C. villosum têm a forma de "pincel-de-estames", são amareladas e ficam expostas acima da copa, em inflorescências terminais. Possuem antese noturna, duram apenas uma noite e secretam cerca de $750 \mathrm{~mL}$ de néctar por noite, características da síndrome de quiropterofilia. A espécie foi visitada por Phyllostomus discolor e morcegos glossofagíneos, assim como por marsupiais arborícolas e mariposas Sphingidae. As polinizações manuais revelaram que C. villosum é autocompatível, embora o número de frutos formados por polinização cruzada seja maior do que o número de frutos resultantes de autopolinizações.

Palavras-chave - biologia floral, Caryocar, chiropterofilia, morcego, sistema reprodutivo

\section{Introdução}

Árvores do dossel são os principais elementos estruturais do ecossistema amazônico, embora apresentem densidades populacionais da ordem de um adulto ou menos por hectare (Chase et al. 1996a,b). A maioria dessas espécies é auto-incompatível, o que indica que suas populações ocupam grandes áreas (Loveless 1992, Hamilton 1999). Segundo Hamrick \& Nason (2000) o tamanho da população de espécies de árvores e a manutenção das mesmas só pode ser inferido com base em informações sobre sistema sexual,

\footnotetext{
1. Parte da Dissertação de Mestrado do primeiro autor, Programa de Pós-Graduação em Ecologia do Instituto Nacional de Pesquisas da Amazônia e Universidade do Amazonas.

2. Universidade Federal do Rio de Janeiro, CCS, IB, Departamento de Botânica, 21941-560 Rio de Janeiro, RJ, Brasil.

3. Instituto Nacional de Pesquisas da Amazônia, Coordenação de Botânica, Caixa Postal 478, 69011-970 Manaus, AM, Brasil.

4. Autor para correspondência: rodr.lemes@gmail.com
}

mecanismos de incompatibilidade, padrão de floração e processo de polinização, o que permite a adoção de estratégias de manejo.

A família Caryocaraceae é composta por 26 espécies distribuídas em dois gêneros, Caryocar e Anthodiscus. Nas áreas adjacentes à cidade de Manaus são encontradas três espécies de Caryocar: $C$. villosum (Aubl.) Pers., C. pallidum A.C. Sm. e C. glabrum Prance \& M.F. da Silva (Prance \& Silva 1973, Prance 1990, Araújo 1995, Ribeiro et al. 1999). Para as espécies relacionadas há registro de visitas de morcegos Phyllostominae e Glossophaginae em C. villosum, assim como dados descritivos da flor (Vogel 1968). Outro estudo relevante foi realizado com Caryocar brasiliense Camb., das áreas de cerrado do Brasil Central, apresentando um sistema auto-compatível e polinização por morcegos Glossophaginae e mariposas Sphingidae (Gribel \& Hay 1993).

Caryocar villosum é uma espécie comum na Amazônia Central, sendo conhecida regionalmente como piquiá. $\mathrm{O}$ fato de ser uma espécie emergente dificulta a 
realização de estudos de biologia floral, fundamentais para a conservação dessa espécie ameaçada pela fragmentação e o interesse comercial na madeira (Prance \& Silva 1973, Vastano \& Barbosa 1983, Araújo 1995). O presente trabalho apresenta dados sobre a biologia floral, comportamento dos polinizadores e sistema de cruzamento de C. villosum.

\section{Material e métodos}

O trabalho foi realizado no Município de Manaus na Reserva Florestal Adolpho Ducke (RFAD - Rodovia

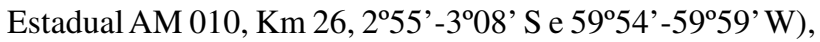
na mata da Universidade do Amazonas (UA) (Planta $3^{\circ} 05^{\prime} 58,59^{\prime \prime} \mathrm{S}$ e $59^{\circ} 58^{\prime} 25,06^{\prime \prime} \mathrm{W}$ ) e em ambiente urbano (Planta 305'38,59" S e 59 59'23,96” W). As observações foram realizadas com o auxílio de duas torres móveis de 24 metros, para acesso aos ramos de árvores altas e ao dossel de árvores baixas. As torres foram usadas para a realização de tratamentos controlados, sendo utilizado equipamento de escalada somente para complementação das observações. O equipamento de escalada permitia acesso ao fuste da árvore, mas não permitia alcançar a porção terminal dos ramos, onde estavam as flores. Para escalada foram utilizadas as técnicas "single rope" descritas por Lamam (1994).

Foram estudadas cinco árvores no segundo semestre de 2000 e uma no segundo semestre de 2001. No segundo ano foi observada uma árvore isolada em ambiente urbano para complementação das observações sobre o comportamento dos visitantes florais. As anotações das características florais e os tratamentos de polinizações controladas foram realizados nos meses de agosto e setembro de 2000, em dias em que não eram feitas observações de visitantes florais.

As observações das flores foram feitas em três noites, concentrando-se em cinco inflorescências focais de três plantas diferentes. As observações tiveram início às $17 \mathrm{~h} 30$ sendo registrados os eventos de antese e as visitações, até a abscisão da flor. Durante as visitações, foi dada atenção especial ao contato de partes florais com os visitantes. Foram considerados os movimentos e duração dos eventos de antese e abscisão de partes florais. As observações findaram com a queda das pétalas. As medidas de partes florais foram feitas por meio de um paquímetro $(0,01 \mathrm{~cm})$ ou trena $(0,1 \mathrm{~cm})$ diretamente no campo. Todas as observações e coletas de dados aconteceram em noites sem chuva.

A quantidade de néctar e a concentração de açúcares no néctar foram amostradas em intervalos de 90 minutos a partir do início da abertura das flores. As flores foram mantidas ensacadas nos períodos entre medições. $\mathrm{O}$ néctar foi coletado com o auxílio de seringa graduada $(0,1 \mathrm{~mL}) \mathrm{em}$ cinco flores por planta. A concentração de açúcares no néctar foi medida com refratômetro manual.
Os experimentos de polinizações manuais foram realizados em três árvores de Caryocar villosum da área da RFAD. Polinizações manuais foram feitas à noite, de $21 \mathrm{~h} 30$ às 23h 30 , em flores previamente ensacadas e emasculadas, $c a$. 12 horas, no mesmo dia. Foram feitos dois tipos de tratamento: (1) autopolinizações, com pólen da mesma planta, e (2) polinizações cruzadas, com o pólen de uma planta a 100 metros da área de estudo. Foram feitos nove tratamentos de polinização cruzada e dez tratamentos de autopolinização por planta. Aproximadamente 15 flores de cada uma das três plantas foram acompanhadas como controle, sendo que algumas flores tiveram antese incompleta. A polinização foi feita arrastando a superfície estigmática em uma lamínula de vidro previamente coberta de pólen. Após a polinização, as flores foram ensacadas novamente até a manhã do dia seguinte. As flores tratadas foram acompanhadas até o período em que os ovários não eram mais abortados, aproximadamente vinte dias após a polinização (15\% do tempo de crescimento e maturação do fruto).

A morfologia das flores foi estudada em flores de seis plantas da RFAD. Cicatrizes, nectários e osmóforos foram avaliadas por meio de vermelho neutro em duas inflorescências de quatro plantas diferentes. Cada inflorescência possuía botões e uma ou duas flores maduras. Os estames menores com base hipertrofiada foram avaliados com relação a viabilidade polínica. Esses pequenos estames foram descritos anteriormente como estaminódios, sensu Prance \& Silva (1973), apesar de produzirem pólen. Dessa forma a contagem de pólen considerou 15 anteras dos estames grandes e 15 anteras dos estames pequenos, sendo retirada uma antera de cada tipo em cinco flores de três plantas diferentes. O pólen foi considerado viável quando corado em vermelho por tetrazólio $(0,2 \%)$. As medidas dos grãos pólen foram feitas em 25 grãos e da superfície estigmática foi medida em três estigmas com o auxilio de microscópio fotônico (ocular: 15 vezes). Exsicatas do material estudado foram depositadas no Herbário do Instituto Nacional de Pesquisas da Amazônia (INPA 206.271).

As observações de visitantes florais foram feitas nos dias: 9, 21, 28 e 29 de agosto de 2000; 12,13 e 14 de novembro de 2000 e nos dias 20,21 e 22 de setembro de 2001. Foi observado um número variável de flores por dia em função da limitação imposta pela localização da torre. Alguns dias de observação foram destinados à obtenção de registros fotográficos. Foram anotados todos os visitantes de 35 flores em seis dias de observação. As observações cobriam desde a antese até a queda das flores, totalizando 60 horas de observação distribuídas irregularmente entre as plantas observadas nos diferentes dias. Na observação de visitantes foram utilizadas lanternas com filtro vermelho para reduzir o efeito da luz sobre o comportamento dos visitantes. A frequiência e o tempo de cada visita foram anotados para descrever o papel do visitante na reprodução da planta. Fotografias auxiliaram a análise do comportamento do visitante e do contato com órgãos reprodutivos da flor. 
Morcegos foram coletados com uma rede de neblina de $1,5 \times 1 \mathrm{~m}$, adaptada para uso sobre a plataforma. A rede de neblina foi disposta próximo às inflorescências, tempo suficiente para coleta e identificação de morcegos. Outros visitantes florais foram coletados com puçá nas noites em que as taxas de visitação não estavam sendo acompanhadas.

\section{Resultados}

A planta - As inflorescências de Caryocar villosum se apresentaram em um pedúnculo longo (tabela 1) e pouco flexível, dispondo as flores acima da folhagem. Em cada inflorescência foram produzidos, em média, $25 \pm 4(n=12)$ botões verde-claros que abriram em número de um ou dois por noite. As sépalas mantiveram a coloração e o tamanho $(3,0 \pm 1,5 \mathrm{~mm})$ à medida que amadureciam. Durante o amadurecimento dos botões as pétalas cresceram até atingir $12,8 \pm 5,5 \mathrm{~mm}$ e se tornaram amarelo-claros. Os botões maduros começaram a abrir entre $17 \mathrm{~h} 00$ e $19 \mathrm{~h} 00$, havendo diferenças até mesmo entre botões da mesma inflorescência.

As flores abriram lentamente com uma seqüência de eventos que duraram de 40 a 90 minutos. As flores de uma mesma árvore demoravam o mesmo tempo para completarem a antese. A seqüência de eventos de abertura começava com o afastamento das cinco pétalas côncavas que lentamente abriam espaço para a saída de algumas anteras. Nessa fase os filetes se encontravam agrupados formando um tufo único, espiralado e comprimido. Qualquer espaço entre as pétalas liberava as anteras que estavam sendo pressionadas pela extensão do tufo de filetes. Antes da abertura completa das pétalas os filetes já se encontravam distendidos. Os estiletes estavam dispostos no centro do tufo de filetes. Entre a base dos filetes e o ovário estava o anel formado pelos pequenos estames.

Pouco antes da abertura e durante toda a antese as flores exalavam odor adocicado e pouco agradável. $\mathrm{O}$ vermelho neutro corou toda a área das pétalas que não estava em contato com outras pétalas antes da abertura do botão, que compreende: face interna das duas pétalas mais internas e a face externa das duas pétalas mais externas.

As pétalas amareladas continuavam a se afastar, sendo acompanhadas pelos estames e pequenos estames, apresentando um padrão hemisférico ao final da antese. Essa estrutura hemisférica foi formada de aproximadamente 230 estames e 40 pequenos estames com filetes brancos e anteras amarelas, tendo ao centro quatro estiletes verde-claros. Os filetes mais curtos que os estiletes (tabela 1) expuseram as anteras $5-20 \mathrm{~mm}$ abaixo do nível dos estigmas. Os pequenos estames apresentaram bases hipertrofiadas, formando uma estrutura anelar ao redor da câmara nectarífera. A base dos pequenos estames foi fortemente corada por vermelho neutro. A câmara nectarífera apresentou raio de $4 \mathrm{~mm}$, porém, tem em seu centro o ovário de onde

Tabela 1. Características morfológicas de flores e inflorescências de Caryocar villosum (Caryocaraceae). Valores médios correspondem a média \pm o desvio padrão $(s)$.

Table 1. Morphological characteristics of Caryocar villosum (Caryocaraceae) flowers and inflorescences. Mean values corespond to average \pm standard deviation.

\begin{tabular}{lc}
\hline Estrutura & Valor médio $\pm s$ \\
\hline Comprimento do pedúnculo da inflorescência $(n=12)$ & $18,0 \pm 4,7 \mathrm{~cm}$ \\
Número de botões por inflorescência $(n=12)$ & $25 \pm 4$ \\
Comprimento das 5 sépalas $(n=6$ flores $)$ & $10,8 \pm 3,1 \mathrm{~mm}$ \\
Comprimento das 5 pétalas $(n=4$ flores $)$ & $26,8 \pm 5,5 \mathrm{~mm}$ \\
Comprimento dos filetes $(n=5$ flores) & $67 \pm 9 \mathrm{~mm}$ \\
Número de estames $(n=5$ flores $)$ & $234 \pm 20$ \\
Comprimento dos estames pequenos $(n=5$ flores) & $26 \pm 5 \mathrm{~mm}$ \\
Número de estames pequenos $(n=5)$ & $41 \pm 5$ \\
Comprimento dos estiletes $(n=5$ flores) & $76,5 \pm 4,0 \mathrm{~mm}$ \\
Diâmetro do pólen dos estames $(n=25$ grãos) & $69,7 \pm 10,5 \mu \mathrm{m}$ \\
Número de grãos de pólen por antera de estame $(n=15$ anteras) & $411,3 \pm 115,6$ \\
Diâmetro do pólen dos estames pequenos $(n=25)$ & $67,8 \pm 7,6 \mu \mathrm{m}$ \\
Número de grãos de pólen em anteras dos estames pequenos $(n=15$ anteras) & $195,7 \pm 79,5$ \\
Diâmetro das 4 superfícies estigmáticas $(n=3$ flores) & $540 \pm 4 \mu \mathrm{mm}$ \\
\hline
\end{tabular}


emergem quatro estiletes. O ovário é tetralocular com um óvulo por lóculo, sendo que de cada lóculo emerge um estilete terminal.

A secreção de néctar ocorreu a partir do início da abertura da flor, quando as anteras começavam a serem expostas. Durante a antese e em todo o período de exposição da flor a quantidade de néctar secretado a cada 90 minutos foi de $164 \pm 52 \mu \mathrm{L}(n=15)$, perfazendo um total de $750 \mu \mathrm{L}$ por flor por noite. A concentração de açúcar foi constante ao longo do período em que a flor estava aberta, em torno de 12,9 $\pm 1,4 \%(n=15)$. As anteras apresentaram deiscência longitudinal e estavam abertas desde o início da antese. O pólen foi liberado em grumos que ficavam pulverulentos após a exposição fora do botão. Qualquer agitação na flor liberava uma nuvem de pólen que se depositava em pétalas e outras peças florais.

$\mathrm{O}$ número médio de grãos de pólen nas anteras dos estames foi de 411,3 $\pm 115,6(n=15)$ e nas anteras dos pequenos estames foi de $195,7 \pm 79,5(n=15)$. A percentagem média de pólen aparentemente não viável nas anteras dos estames foi de $9,28 \%$, variando de $5 \%$ a $21 \%(n=15)$. Nas anteras dos pequenos estames a percentagem média de pólen inviável foi de 20,25\%, variando de $4 \%$ a $55 \%(n=15)$. Multiplicando o número de grãos de pólen das anteras pelo número médio de estames (234) e pequenos estames (41) a produção estimada de pólen por flor foi 94.366,7 grãos, sendo que $89,16 \%$ são viáveis. A média da área da circunferência do pólen é de $3,8 \mu \mathrm{m}^{2} \pm 0,5(n=25)$ e cada superfície estigmática apresentou área de 23,6 $\pm 0,5 \mu \mathrm{m}^{2}(n=3)$, permitindo o contato direto de aproximadamente 6-7 grãos de pólen com a superfície estigmática.

Em três plantas da RFAD, todas ou parte das flores de algumas inflorescências tiveram antese incompleta apresentando todos ou parte dos estigmas e estiletes não distendidos e murchos. Nessas flores a produção de néctar podia ou não ser comprometida, porém não houve diferença na liberação do pólen.

Entre $0 \mathrm{~h} 00$ e $2 \mathrm{~h} 30$, as pétalas, estames e pequenos estames caíam. Na planta, restavam apenas o pistilo e as sépalas, concluindo um ciclo de aproximadamente 7 horas em que a flor é funcionalmente atrativa.

Os tratamentos de autopolinização e de polinização cruzada resultaram respectivamente $6,9 \%$ e $14,8 \%$ de sucesso na produção de frutos. Dentre as flores usadas como controle apenas as com antese completa produziram frutos (tabela 2).

Visitantes florais - Por volta de 17h00, antes do anoitecer, foram registrados os primeiros visitantes que incluíam: beija-flores - Heliothryx aurita (Gmelin, 1788),
Tabela 2. Resultados dos testes de polinização controlada nas flores de Caryocar villosum (Caryocaraceae), Amazônia Central.

Table 2. Results of controled pollination treatments in Caryocar villosum (Caryocaraceae) flowers, Central Amazon.

\begin{tabular}{|c|c|c|c|}
\hline Tratamento & $\begin{array}{l}\text { Número de } \\
\text { flores }\end{array}$ & $\begin{array}{l}\text { Número de } \\
\text { frutos }\end{array}$ & $\begin{array}{c}\text { Sucesso } \\
\text { em } \%\end{array}$ \\
\hline Autopolinização & 29 & 2 & 6,9 \\
\hline Polinização cruzada & 27 & 4 & 14,8 \\
\hline $\begin{array}{l}\text { Polinização aberta } \\
\text { (controle) }\end{array}$ & 33 & 1 & 3,0 \\
\hline $\begin{array}{l}\text { Polinização aberta } \\
\text { (flores com antese } \\
\text { incompleta) }\end{array}$ & 17 & 0 & 0 \\
\hline
\end{tabular}

Amazilia versicolor (Vieillot, 1818), Thalurania furcata (Gmelin, 1788) (Trochilidae), abelhas (Apidae), besouros (Lampiridae) e mariposas (Noctuidae).

Os beija-flores visitaram as flores até o anoitecer (18h30), introduzindo o bico por entre a pequena abertura das pétalas e tocando as poucas anteras expostas. As abelhas e besouros coletaram apenas o pólen depositado nas peças florais e anteras. Mariposas Noctuidae pousavam nas sépalas e colocavam a probóscide por entre as pétalas até a câmara nectarífera. Após o crepúsculo, os besouros e mariposas continuaram a visitar as flores, porém as atividades de mariposas Sphingidae, morcegos Phyllostomidae e pequenos mamíferos não voadores foram mais intensas. Uma das plantas da RFAD manteve suas flores até as $7 \mathrm{~h} 20$ do dia seguinte, sendo visitada por abelhas e beija-flores a partir das $5 \mathrm{~h} 40$.

Os morcegos foram verificados somente em plantas que não estavam nas áreas da RFAD. Com base nas 20 flores acompanhadas nos três dias de observação, realizados fora das áreas da Reserva, os morcegos foram os visitantes mais freqüentes $\left(13,0 \pm 1,2\right.$ visitas $\left.\mathrm{h}^{-1}\right)$. Em plantas que não foram freqüentadas por morcegos, o número de visitas de mariposas Noctuidae foi superior ao de outros visitantes (aproximadamente 4 visitas $\mathrm{h}^{-1}$ ). Os grupos de morcegos registrados foram: Glossophaginae e Phyllostomus discolor (Wagner, 1843).

As visitas de $P$. discolor iniciaram por volta das 19h00, quando as pétalas das flores estavam afastadas o suficiente para expor a câmara nectarífera. As visitas diminuíram quando as flores começavam a perder as pétalas, estames e pequenos estames. A queda de peças florais foi favorecida pela visitação de morcegos. Com 
o início da abscisão de partes florais, poucos morcegos continuavam a se alimentar do néctar preso aos pequenos estames.

Os grupos de $P$. discolor sobrevoavam a árvore e visitavam as flores acima da copa. As flores mais internas à copa pareciam ser acessadas pelos vãos entre os aglomerados de folhas dos diferentes galhos. Os morcegos pousavam sobre a inflorescência durante as visitas, o que durava aproximadamente $1,0 \pm 0,4 \mathrm{~s}(n=22$ medições). Os morcegos chegavam por cima da flor e colocavam a cabeça dentro da mesma, mantendo as asas abertas, acima da inflorescência (figura 1). Ainda com a cabeça dentro da flor, os morcegos arqueavam as asas para possibilitar a saída da inflorescência, por cima ou por baixo da copa. Foi capturado apenas um exemplar de $P$. discolor, durante as capturas com rede na torre.

Durante o contato com a flor, $P$. discolor colocava o focinho dentro do anel de anteras, provavelmente coletando o néctar acumulado. A aproximação por cima era suficiente para que o morcego tocasse os estigmas e grande parte das anteras de uma ou mais flores, durante o pouso (figura 1). Assim, o pólen de C. villosum era depositado praticamente em toda a região ventral do morcego, incluindo asas e eventualmente na cabeça. As visitas de $P$. discolor ocorreram em intervalos de 2 a 10 minutos.

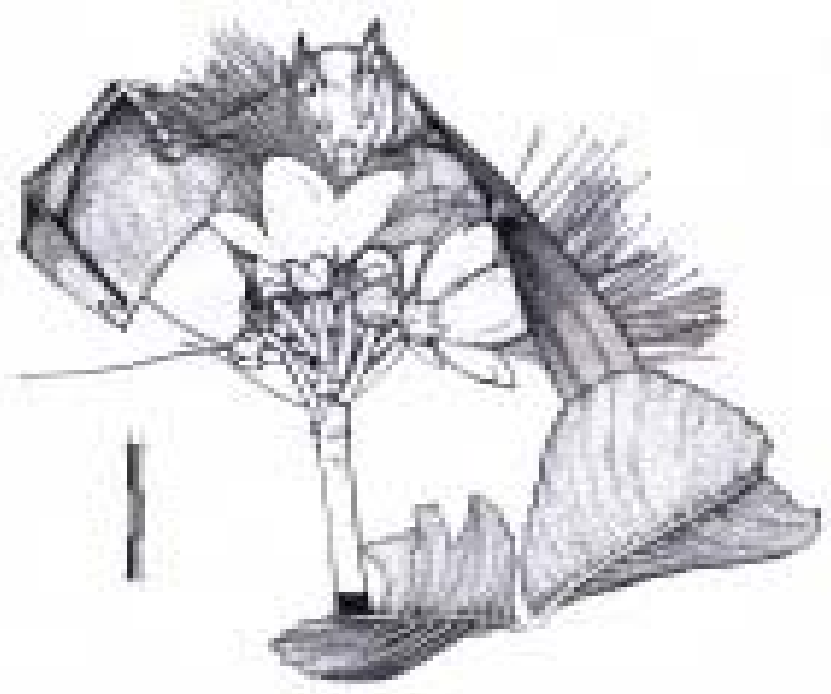

Figura 1. Esquema produzido a partir de uma foto da visita de Phyllostomus discolor (Phyllostomidae). Note que Phyllostomus discolor pousa sobre inflorescência e toca grande parte das anteras das flores da inflorescência. Barra $=3 \mathrm{~cm}$.

Figure 1. Representation from a photo of Phyllostomus discolor (Phyllostomidae). Note that Phyllostomus discolor lands over the inflorescence and touch all flowers. Bar $=3 \mathrm{~cm}$.
As flores no interior da copa, geralmente não foram visitadas por $P$. discolor, mas por morcegos glossofagíneos. O registro fotográfico de morcegos glossofagíneos indica que os visitantes desse grupo apresentam uropatágio desenvolvido, características dos morcegos dos gêneros: Glossophaga, Lonchophylla e Lionycteris.

Os glossofagíneos aproximavam-se rapidamente da inflorescência e faziam breve vôo adejado em frente à flor. Nessa posição, estendiam as asas para traz e lançavam a cabeça para frente, colocando o focinho dentro da flor. Os morcegos glossofagíneos faziam várias incursões rápidas (< 1s) à mesma flor, descrevendo sempre a mesma rota. Devido ao tamanho corporal dos glossofagíneos, é possível que toquem somente as anteras pelo lado em que foi feita aproximação e visita, não tocando os estigmas que estão no centro do anel de anteras (figura 2).

Phyllostomus discolor forrageavam em grupos visitando as plantas em intervalos regulares (figura 4). Entretanto visitas de morcegos solitários foram registradas ao final da noite quando a maior parte das flores já haviam caído. O mesmo padrão de visitas não foi registrado em plantas observadas no ano 2000. Os

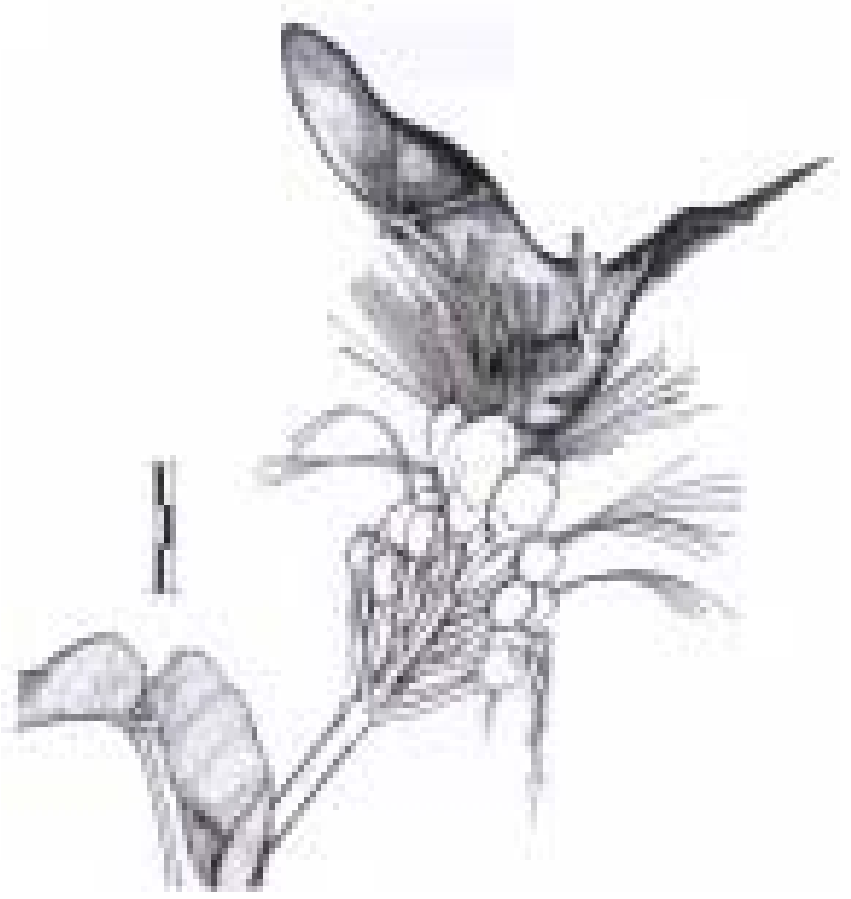

Figura 2. Esquema produzido a partir de uma foto da visita de morcego glossofagíneo. Note que morcegos glossofagíneos tocam somente parte das anteras e estigmas. Barra $=3 \mathrm{~cm}$.

Figure 2. Representation from a photo of glossophagine visit. Note that glossophagine bats touches only fractions of anthers and stigma. $\mathrm{Bar}=3 \mathrm{~cm}$. 
registros de visitação de morcegos apresentaram um valor máximo de 100 visitas em uma flor.

Nas noites de observação de plantas da RFAD, não foram registradas visitas de morcegos, mas somente a presença de mamíferos não-voadores e mariposas. As visitas das mariposas Sphingidae ocorreram durante toda à noite, porém não ultrapassaram duas visitas por noite em cada flor. A visitação era realizada durante vôo adejado em que a mariposa tocava estigmas e anteras enquanto colocava a probóscide no interior da câmara nectarífera (figura 3). Essas visitas duravam apenas alguns segundos, durante os quais a mariposa voava irregularmente sobre a flor. Durante o trabalho foi coletado apenas um indivíduo de Pachylia ficus (Linnaeus, 1758), com uma espirotromba de 47,2 $\mathrm{mm}$.

Dentre os mamíferos não voadores que freqüentaram as flores do piquiá estão Caluromys lanatus (Olfers, 1818) e C. philander (Linnaeus, 1758) (Didelphimorphia, Caluromyidae). Registrou-se a presença de grupos de até sete indivíduos de Caluromys spp. forrageando nas flores de uma única árvore (18-09-2000 - 23h00) da RFAD. As visitas ocorreram sem um padrão regular, porém, dentre as flores observadas, nenhuma foi visitada mais de uma vez. Esses mamíferos caminhavam pelos galhos da planta e, usando a cauda para se equilibrar, chegavam até as inflorescências na extremidade dos galhos. Durante as visitas seguravam a inflorescência e colocavam o focinho dentro das flores abertas tocando com a cabeça anteras e estigmas.

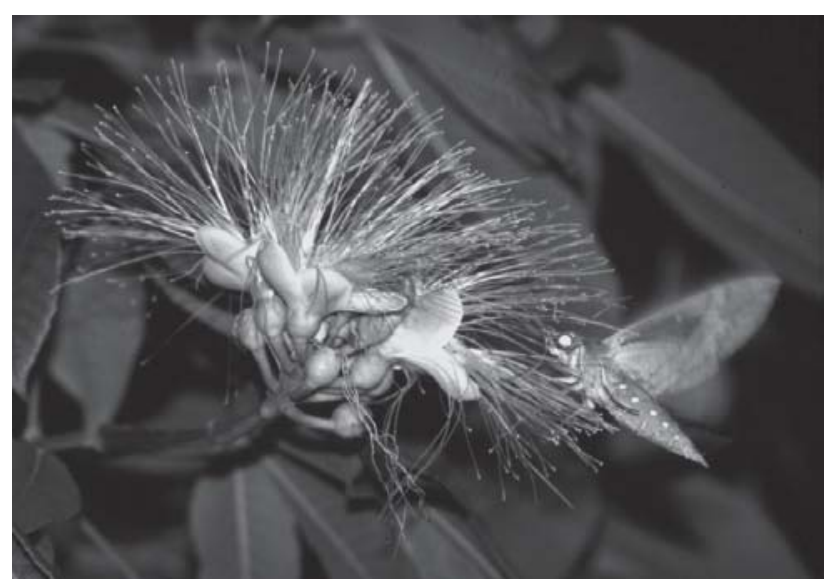

Figura 3. Visita de Esfingídeo à flor de Caryocar villosum (Caryocaraceae) de uma árvore na Reserva Florestal Adopho Ducke.

Figure 3. Sphinx hawkmoths visit to Caryocar villosum (Caryocaraceae) flower in a tree at The Reserva Florestal Adolpho Ducke.

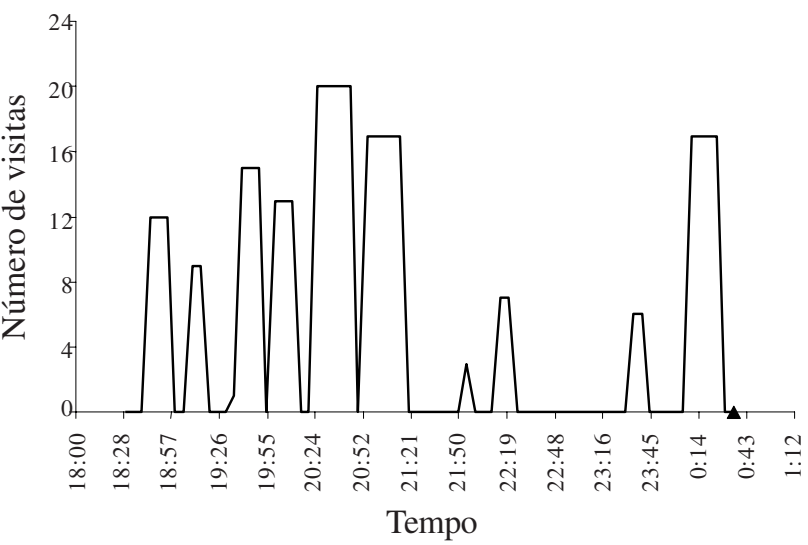

Figura 4. Número de visitas, horário e duração das ondas de atividade de Phyllostomus discolor (Phyllostomidae) em 13 inflorescências (28 flores) de um indivíduo de Caryocar villosum (Caryocaraceae) na área urbana. $\mathbf{\Delta}=$ início do período em que as flores perdem o perianto.

Figure 4. Number of visits, time and activity span of Phyllostomus discolor (Phyllostomidae) visiting bouts in 13 inflorescences (28 flowers) of a Caryocar villosum (Caryocaraceae) tree at an urban area. $\boldsymbol{\Delta}=$ flowers starts to drop the perianth.

\section{Discussão}

Caryocar villosum é uma espécie com características típicas da síndrome de quiropterofilia (Baker 1960). Dentre essas características destacamse: antese noturna, coloração amarelada, estruturas resistentes e amplas, grande quantidade de néctar secretado, localização exposta, odor forte e pouco agradável, além de grande quantidade de pólen.

Antese crepuscular, produção de néctar desde o início da antese e a liberação de odor antes da abertura favorecem a inclusão da planta em rotas de forrageamento "trap line", que são definidas no início da atividade dos morcegos (Heithaus 1982). A abertura lenta contrasta com o registrado em outras plantas quiropterófilas, como Ceiba pentandra (L.) Gaertn. (Gribel et al. 1999), C. acuminata (S. Watson) Rose (Baker 1960), Pseudobombax longiflorum (Mart. \& Zucc.) A. Robyns (Rocha et al. 1991) e Passiflora mucronata Lam. (Sazima \& Sazima 1978), onde abertura é rápida ou quase explosiva.

A constante produção de néctar durante todo o período de antese favorece o retorno do polinizador à mesma planta ao longo da noite. O néctar é armazenado na ampla câmara nectarífera além de ficar preso por aderência aos pequenos estames. Sazima \& Sazima 
(1978) discutiram a função dos estaminódios na redução da perda de néctar em flores quiropterófilas. Armazenar néctar nos estaminódios permitiria o acesso de morcegos maiores com altas demandas metabólicas, sendo mais eficiente do que flores com corolas tubulares. A produção contínua de grande volume de néctar e a grande quantidade de flores, maior que a produção de frutos, pode contribuir para o aumento do "display" necessário à atração de visitantes como Phyllostomus discolor, cuja estratégia de forrageamento, solitária ou em grupo, depende da disponibilidade de flores (Sazima \& Sazima 1977).

Em algumas plantas quiropterófilas, o aumento na deposição de pólen sobre o polinizador é favorecido pelo aumento do tamanho da antera, como é o caso de Passiflora mucronata (Sazima \& Sazima 1978). Também é comum que todas as flores da inflorescência, atuem na deposição de pólen no corpo do vetor como observado em flores de Ceiba (Baker 1960, Gribel et al. 1999). A disposição dos estames em forma hemisférica torna impossível acessar a câmara nectarífera sem que se toque nas anteras, fato que também pode ser associado a polinização por morcegos grandes (Baker 1960, Gribel et al. 1990). Flores quiropterófilas zigomórficas, que normalmente depositam pólen em uma região definida do corpo de morcegos, estão mais relacionadas com morcegos menores como os glossofagíneos (Sazima \& Sazima 1978, Gribel et al. 1990, Hokche \& Ramirez 1990).

Em interações em que o polinizador tem um grande tamanho corporal, a alta produção de pólen aumenta as chances de cruzamento (Heithaus et al. 1974). Essa produção se torna mais importante quando a flor apresenta uma reduzida superfície estigmática (Gribel $\&$ Hay 1993). No caso de C. villosum a flor apresenta quatro superfícies estigmáticas onde podem se alojar 6-7 grãos de pólen em cada uma, porém produz cerca de 84.000 grãos viáveis. Gribel \& Hay (1993) encontraram resultados similares para Caryocar brasiliense Camb., na qual a superfície estigmática dessa espécie recebe apenas de 4-6 grãos de pólen. De acordo com Cruden (1977), 2-7 grãos de pólen por óvulo são necessários para garantir a produção de tubos polínicos e a formação do fruto. Nesse sentido, em C. villosum e C. brasiliense, a quantidade de pólen que entra em contato com o estigma fica bem próxima do limite do comprometimento da polinização. Considerando a razão pólen/óvulo (20.000:1), C. villosum pode ser considerada espécie xenógama segundo Cruden (1977), porém, a alta produção de pólen deve estar relacionada com a reduzida superfície estigmática e com o tamanho do polinizador.

A autopolinização não deve ser comum em polinizações naturais devido a hercogamia (Heithaus et al. 1974, Gribel \& Hay 1993) e à reduzida superfície estigmática. Dessa forma a taxa de autofecundação pode estar diretamente relacionada ao fluxo de pólen promovido pelo polinizador. C. brasiliense, apesar de definida como uma espécie autocompatível, apresenta maior produção de frutos em cruzamentos (Gribel \& Hay 1993). Estudos com marcadores microssatélites mostraram uma alta taxa de polimorfismo nas progênies de $C$. brasiliense, o que foi atribuído à alta taxa de cruzamento promovida pelos morcegos (Collevatti et al. 2001).

O presente estudo, em comparação com os resultados obtidos por Gribel \& Hay (1993), mostrou que $C$. brasiliense e $C$. villosum são muito similares em relação à biologia floral. Assim como em C. brasiliense, C. villosum apresenta um grande número de visitantes florais. Gribel \& Hay (1993) observaram que a polinização por mariposas em C. brasiliense depende do tamanho da probóscide, concluindo que Sphingidae que possuem a probóscide menor ou do mesmo tamanho dos estiletes podem atuar como polinizador. Em C. villosum os esfingídeos que foram observados em atividade na flor apresentam um tamanho de probóscide que favorece o contato com as anteras, reforçando a importância desses insetos na polinização da espécie.

Morcegos Glossophaginae visitaram principalmente flores da parte baixa da copa que não foram acessadas por Phyllostomus discolor. Essa divisão espacial das flores, entre as duas espécies de morcegos foi registrada também em Bauhinia (Heithaus et al. 1974, Fischer 1992). Não foi possível registrar a adoção da estratégia do tipo "trap line" em Glossophaginae, embora esta estratégia seja reportada em outras plantas (Sazima et al. 1999). As visitas repetidas em apenas uma flor e a provável ausência de comportamento "trap line" podem estar afetando o número de cruzamentos realizados por Glossophaginae em C. villosum. Os registros fotográficos não confirmaram o contato do estigma de C. villosum com o corpo dos glossofagíneos, porém esse grupo de morcegos são polinizadores efetivos de C. brasiliense (Gribel \& Hay 1993).

$O$ fato de $P$. discolor ser maior que Glossophaginae, fornecendo uma superfície maior de deposição de pólen e entrando em contato com um número maior de flores, sugere que esta espécie seja a principal polinizadora de C. villosum. Esse morcego visita as flores em grupos de indivíduos durante a execução de um trajeto que inclui 
várias plantas. Essa estratégia gera um padrão conhecido como "ondas de forrageamento", pois uma mesma planta é visitada em intervalos regulares (Heithaus et al. 1974). A adoção desses trajetos se dá em função da quantidade de flores existentes em cada planta e favorece cruzamentos entre indivíduos em floração.

A ausência de visitas de morcegos e o aumento frequiência relativa das visitas de marsupiais nãovoadores em plantas da RFAD não era esperado, devido aos registros prévios de visitas de $P$. hastatus (Pallas 1767), P. discolor e Glossofagineos em C. villosum por Vogel (1968). Os morcegos só foram definidos como os polinizadores mais importantes depois das observações de plantas em áreas urbanas. A importância de morcegos é definida com base na freqüência de visitação por inflorescência focal e na capacidade de promover cruzamentos a longa distância, conforme o estudo comparativo da diversidade genética das progênies de plantas de C. villosum polinizadas por morcegos e marsupiais arborícolas (R.L. Martins, M.R. Lemes \& R. Gribel dados não publicados). O fluxo de pólen promovido pelos mamíferos não voadores pode variar em função do deslocamento desses animais, o que está relacionado ao metabolismo animal e à quantidade de recurso oferecido (Gribel 1988, Carthew \& Goldingay 1997). Caluromys lanatus e C. philander foram os visitantes mais freqüentes na RFAD, porém esses animais têm uma mobilidade pequena concentrando sua atividade de forrageamento em apenas uma árvore por noite (Janson et al. 1981). Para uma árvore que ocorre a baixas densidades na floresta primária, como $C$. villosum na Amazônia, a polinização cruzada promovida por Caluromys, provavelmente, não é tão alta quanto a taxa de cruzamento resultante da visitação de morcegos.

A adoção de um mecanismo de autogamia facultativa e a manutenção de um sistema de polinização pouco especializado ou "aberto" pode ser vantajosa para Caryocar villosum, já que as variações na frequiência de potenciais polinizadores, de um local para outro, diminuem a previsão de visita por um polinizador específico e mais especializado (Elmqvist et al. 1992, Murawski \& Hamrick 1992, Waser 1993, Waser \& Price 1993).

Agradecimentos - A Antonio C. Webber, Edivani V. Franceschinelli, Maristerra R. Lemes, Paulo Eugênio A.M. de Oliveira, Rosane G. Collevatti e Fábio R. Scarano, pelas considerações e correções no conteúdo do manuscrito. A Catarina da Silva Motta, pela identificação das mariposas. A Marcelo L. de Queiróz, Viviane Layme, Leonardo França, Aldenora Queirós, Cristiano M. de Souza e Alexandre Colleto,
Daniel M.C. Santos pelo apoio em campo e edição do trabalho. Ao INPA via PPI 2-3310 e PPG-7, e PDBFF (projeto de colaboração entre INPA e Smithsonian Tropical Research Institute) pelo apoio técnico e financeiro. Ao CNPq, ao Fundo Mundial para a Natureza (WWF e USAID) e à Fundação Botânica Margaret Mee, pelo apoio financeiro.

\section{Referências bibliográficas}

ARAÚJO, F.D. 1995. A review of Caryocar brasiliense (Caryocaraceae) - an economically valuable species of the Central Brazilian Cerrados. Economic Botany 49:40-48.

BAKER, H.G. 1960. The adaptation of flowering plants to nocturnal and crepuscular pollinations. Quarterly Review of Biology 36:64 -73.

BAWA, K.S. 1990. Plant-pollinator interactions in tropical rain forests. Annual Review of Ecology and Systematics 21:399-422.

CARTHEW, S.M. \& GOLDINGAY, R.L. 1997. Non-flying mammals as pollinators. Trends in Ecology and Evolution 12:104-108.

CHASE, M.R., KESSELL, R. \& BAWA, K. 1996a. Microssatellite markers for population and conservation genetics of tropical trees. American Journal of Botany 83:51-57.

CHASE, M.R., MOLLER, R.C., KESSELL, R. \& BAWA, K. 1996b. Distant gene flow in tropical trees. Nature 383:398-399.

COLLEVATTI, R.G., GRATTAPAGLIA, D.B. \& HAY, J.D. 2001. High resolution microsatellite based analysis of the mating system allows the detection of significant biparental imbreeding in Caryocar brasiliense, an endangered tropical tree species. Heredity 86:60-67.

CRUDEN, R.W. 1977. Pollen-ovule ratios: a conservative indicator of breeding systems in flowering plants. Evolution 31:32-46.

ELMQVIST, T., COX, P.A., RAINEY, W.E. \& PIERSON, E.D. 1992. Restricted pollination on oceanic islands: Pollination of Ceiba pentandra by flying foxes in Samoa. Biotropica 24:15-23.

FISCHER, E. 1992. Foraging of nectarivorous bats on Bauhinia ungulata. Biotropica 24:579-582.

GRIBEL, R. 1988. Visits of Caluromys lanatus (Didelphidae) to flowers of Pseudobombax tomentosum (Bombacaceae): a probable case of pollination by marsupials in Central Brazil. Biotropica 20:344-347.

GRIBEL, R. \& HAY, J.D. 1993. Pollination ecology of Caryocar brasiliense (Caryocaraceae) in Central Brazil cerrado vegetation. Journal of Tropical Ecology 9:199-211.

GRIBEL, R., SAZIMA, I. \& SAZIMA, M. 1990. Flores pedem morcegos. Ciência Hoje 11:22-28.

GRIBEL, R., GIBBS, P.E. \& QUEIRÓZ, A.L. 1999. Flowering phenology and pollination biology of Ceiba pentandra (Bombacaceae) in Central Amazonia. Journal of Tropical Ecology 15:247-263. 
HAMILTON, M.B. 1999. Tropical tree gene flow and dispersal. Nature 401:129-130.

HAMRICK, J.L. \& NASON, J.D. 2000. Gene flow in forest trees. In Forest conservation genetics: Principles and practice (A. Young, D. Boshier \& T. Boyle, eds.). CSIRO Publishing/CABI Publishing, Queensland, p.81-90.

HEITHAUS, E.R. 1982. Coevolution between bats and plants. In Ecology of bats (T.H. Kunz, ed.). Plenum Press, New York, p.287-325.

HEITHAUS, E.R., OPLER, P.A. \& BAKER, H.G. 1974. Bat activity and pollination of Bauhinia pauletia: plantpollinator coevolution. Ecology 55:412-419.

HOKCHE, O. \& RAMIREZ, N. 1990. Pollination ecology of seven species of Bauhinia L. (Leguminosae: Caesalpinioideae). Annals of the Missouri Botanical Garden 77:559-572.

JANSON, C.H., TERBORGH, J. \& EMMONS, L.H. 1981. Nonflying mammals as pollinating agents in the amazonian forest. Biotropica 13(supl.):1-6.

LAMAN, T. 1994. Safety recommendations for climbing rain forest trees with 'single rope technique.' Biotropica 27:406-409.

LOVELESS, M.D. 1992. Isozyme variation in tropical trees: patterns of genetic organization. New Forest 6:67-94.

MURAWSKI, D.A. \& HAMRICK, J.L. 1992. Mating system and phenology of Ceiba pentandra (Bombacaceae) in Central Panama. Journal of Heredity 83:401-404.

PRANCE, G.T. 1990. The genus Caryocar L. (Caryocaraceae): an underexploited tropical resource. Advances in Economic Botany 8:177-188.

PRANCE, G.T. \& SILVA, M.F. 1973. Caryocaraceae. Flora Neotropica Monograph 12:1-75.

ROCHA, I.R.D., MORAIS, H.C. \& KITAYAMA, K. 1991. Visitantes diurnos de flores quiropterófilas. Revista Brasileira de Biologia 51:249-256.
RIBEIRO, J.E.L.S., HOPKINS, M.J.G., VICENTINE, A., SOTHERS, C.A., COSTA, M.A.S., BRITO, J.M., SOUZA, M.A.D., MARTINS, L.H.P., LOHMANN, L.G., ASSUNÇÃO, P.A.C.L., PEREIRA, E.C., SILVA, C.F., MESQUITA, M.R. \& PROCÓPIO, L.C. 1999. Flora da Reserva Ducke: Guia de Identificação das Plantas Vasculares de uma Floresta de Terra Firme na Amazônia Central. INPA, Manaus.

SAZIMA, I. \& SAZIMA, M. 1977. Solitary and group foraging: two flower-visiting patterns of the lesser spear-nosed bat Phyllostomus discolor. Biotropica 9:213-215.

SAZIMA, M. \& SAZIMA, I. 1978. Bat pollination of the passion flower, Passiflora mucronata in Southeastern Brazil. Biotropica 10:100-109.

SAZIMA, M., BUZATO, S. \& SAZIMA, I. 1999. Batpollinated flower assemblages and bat visitors at two atlantic forest sites in Brazil. Annals of Botany 83:705-712.

VASTANO, B.J.T. \& BARBOSA, A.P. 1983. Propagação vegetativa do piquiá (Caryocar villosum Pers.) por estaquia. Acta Amazonica 13:143-148.

VOGEL, S. 1968. Chiropterophilie in der Neotropischen Flora. Neue Mitteilungem I. Flora Abteilung B 1578:562-602.

WASER, N.M. 1993. Population structure, optimal outbreeding, and assortative mating in angiosperms. In The natural history of inbreeding and outbreeding. Theoretical and empirical perspectives (N.W. Thornhill, ed.). University of Chicago Press, Chicago, p.173-199.

WASER, N.M. \& PRICE, M.V. 1993. Specialisation and generalisation in pollination systems. In Pollination in Tropics (G.K. Veeresh, R. Uma Shaanker \& K.N. Ganeshaiah, eds.). International Union for the Study of Social Insects, Bangalore, p.165-169. 